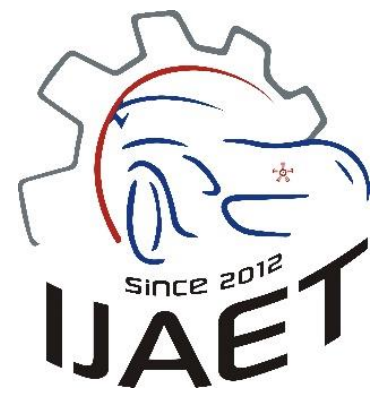

e-ISSN: 2146 - 9067

International Journal of Automotive

Engineering and Technologies

journal homepage:

https://dergipark.org.tr/en/pub/ijaet

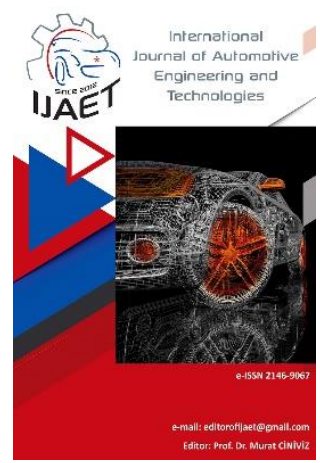

Original Research Article

\title{
Effects of design and operating parameters on the performance of a quasi-realistic Diesel cycle engine
}

\author{
Bayram Kılıç ${ }^{1}$ Emre Arabac1 ${ }^{2, *}$
}

\begin{abstract}
${ }^{1}$ Burdur Mehmet Akif Ersoy University, Vocational School of Technical Sciences, Department of Electrical and Energy, Program of Hybrid and Electric Vehicles Technologies, Burdur, Turkey.

${ }^{2}$ Burdur Mehmet Akif Ersoy University, Vocational School of Technical Sciences, Department of Motor Vehicles and Transportation Technologies, Program of Automotive Technologies, Burdur, Turkey.
\end{abstract}

\section{ARTICLE INFO}

1. $0000-0002-8577-1845$

2. $0000-0002-6219-7246$

Doi: $10.18245 /$ ijaet.816130

* Corresponding author earabaci@mehmetakif.edu.tr

Received: Dec 25, 2020

Accepted: Jan 26, 2021

Published: Mar 31, 2021

Published by Editorial Board Members of IJAET

(C) This article is distributed by Turk Journal Park System under the $\mathrm{CC} 4.0$ terms and conditions.

\begin{abstract}
Although Diesel engines have begun to be abandoned in the automotive industry due to the emission legislations of the world, they are still widely used in generators, work machines, agricultural machines, and heavy vehicles due to their high power density and thermal efficiency. The classical Diesel cycle, which is the thermodynamic cycle of Diesel engines, was developed by taking into account irreversibilities, heat transfer losses, friction, and gas exchange process, and a quasi-realistic Diesel cycle was obtained. Also, the working fluid of the Diesel cycle has been accepted as an air-fuel-residual gas mixture instead of air. This Diesel cycle model is very useful to examine the effect of Diesel engines' design and operating parameters on engine performance. For this study, the effect of variation in equivalence ratio, stroke-bore ratio, and compression ratio on engine performance was examined. Thermal efficiency, maximum temperature, exhaust temperature, fuel consumption, and specific fuel consumption are used as engine performance parameters. The characteristics and operating conditions of a Diesel engine in a power generator were used for the numerical study. Engine performance increased by increasing the equivalence ratio, which is the engine operating parameter. When the compression ratio, which is the structural parameter, increased, the engine performance increased, but the maximum temperature also increased, although it was not desired. Therefore, it is necessary to optimize the compression ratio and the maximum temperature. Again, when the stroke-bore ratio, which is a structural parameter, was increased, engine performance decreased, but the maximum temperature decreased as desired. For optimization of the two structural parameters, compression ratio, and stroke-bore ratio, it is necessary to decrease the stroke-bore ratio while increasing the compression ratio. The results obtained with the numerical study using the created model are guiding for engine designers.

Keywords: Diesel cycle, finite-time thermodynamics, performance
\end{abstract}

\section{Introduction}

Until a few years ago, Diesel-powered vehicles were very popular, and Diesel-powered vehicles were more popular than gasoline- 
powered vehicles, especially due to their low fuel consumption. The reports of the World Health Organization (WHO) on nitrogen-oxides (NOx) and particle matter (PM) emissions have reduced the interest in Diesel engines in the automotive industry [1]. For this reason, most of the automotive manufacturers in the world have given up their research and development activities on Diesel-powered vehicles. This decision also negatively affected vehicle users, causing a decrease in the sales of Dieselpowered vehicles. Also, most of the vehicle models marketed today do not have a Diesel engine option anymore. However, Diesel engines are not only used in the automotive industry. Today, Diesel engines are used in generators, locomotives, ships, agricultural machinery, and many other machines [2]. Due to the advantages of Diesel engines such as high power density, high torque capability, and being economical, they are still used in industries other than the automotive industry.

The thermodynamic cycles of internal combustion engines are ideal air standard cycles. In these cycles, parameters such as friction, irreversibilities, combustion, heat losses, gas-exchange are neglected and these cycles occur in infinite time. In these cycles that occur in infinite time, all operations are performed quasi-static, so the cycle work is maximum and the cycle power is zero. Therefore, it is difficult to determine the actual engine performance using ideal cycle models. Also, parametric studies that can be done in such classical cycles are quite limited [3]. Cycle models in which these cycles in classical thermodynamics are assumed to take place in finite time and parameters such as friction, irreversibilities, combustion, heat losses, gasexchange are taken into account, are within the scope of finite-time thermodynamics in modern thermodynamics. Since realistic operating parameters are used in such cycles, the results obtained are very close to the actual engine cycles. For this reason, such cycles can be called quasi-realistic cycles. In finite-time thermodynamics, cycles are internally reversible and can therefore also be called endoreversible cycles [4].

In finite time engine cycle models, the effect of design and operating parameters such as equivalence ratio, stroke length, cylinder wall temperature, cylinder diameter, inlet temperature, inlet pressure, working fluid, compression ratio, and engine speed can be examined [3]. In previous studies, it is seen that finite-time thermodynamics is frequently used to examine the performance of real engine cycles. In finite-time thermodynamics, specific heats can be considered constant (temperatureindependent) [5] or it can be accepted as a function of temperature (temperaturedependent) [6]. Only air [7], air-fuel mixture [8], or air-fuel-residual gas mixture [9] can be used as the working fluid. Finite-time thermodynamics can be applied to all engine cycles such as Otto, Diesel, Dual, Miller, Atkinson, and parametric studies or comparisons between cycles can be made [1013]. Also, the effects of parameters such as variable compression ratio, late inlet valve closing method, turbocharger and alternative fuel mixture gas exchange process applied in today's engines on engine performance can be modeled simply by using finite-time thermodynamics [14-18].

There are many studies in the literature on the application of finite-time thermodynamics to engine cycles, and some of the studies examined in this context have been summarized. Ebrahimi considered friction losses and heat transfer losses in the cycle model while examining the effect of volume ratio in the heat-rejection process on the Atkinson cycle performance [5]. You et al. modeled the isentropic processes occurring in the dual shaft cycle as a polytropic process, taking into account heat transfer losses. In their study, power output, thermal efficiency, entropy generation rate, and ecological function parameters were investigated in detail [6]. Ge et al. carried out ecological optimization by using variable specific temperatures in the irreversible Otto cycle. They took into account internal irreversibility loss, friction loss, and heat transfer loss in their studies and reported that their results could be used for actual Otto cycle engine performance optimization [7]. Ebrahimi presented the effects of equivalence ratio, cylinder wall temperature, and mean piston speed on performance in his study on Atkinson engine. He reported that the results obtained can be used in the design of the actual Atkinson engine [8]. Zhao et al conducted a study for the irreversible heat model with three typical 
thermodynamic cycles and its optimum performance analysis. In these studies, they considered heat transfer loss and examined design parameters for maximum power output. With this study, they have obtained important results for maximum power output and efficiency in dual, Otto, and Diesel cycles [12]. Gonca et al. examined the late intake valve closing application for the air-standard irreversible dual-Miller cycle. In their study, they considered many parameters such as stroke ratio, cut-off ratio, pressure ratio, isentropic efficiencies, and optimum performance conditions were determined for the dual-Miller cycle [14]. Gonca et al. conducted a theoretical and experimental study for a Diesel engine powered by a Diesel-bio Diesel blend. In their study, they transferred the data they obtained from the experimental data to the theoretical model. For this, they obtained an empirical expression by using experimental data for the combustion efficiency in the theoretical model [16]. It is seen that the results obtained in these studies are similar to the actual engine performance. However, in none of these studies a model related to intake and exhaust (gasexchange) processes were created. For this reason, environmental conditions or a constant value have been accepted for the cycle initial conditions.

In this study, the effects of the change in the stroke-bore ratio, compression ratio, and equivalence ratio parameters on the engine performance by taking the operating conditions and dimensions of a Diesel engine (natural aspirated, air-cooled, single-cylinder) power generator as a reference were examined using a quasi-realistic Diesel cycle model and the results obtained were discussed. Also, different from the studies in the literature, gas-exchange processes are modeled in this study. Thus, a cycle model that is more comprehensive than the literature and closer to the actual engine cycle has been created.

\section{Quasi-Realistic Diesel Cycle Engine Model}

In classical thermodynamics, the Diesel cycle consists of isentropic compression and expansion strokes, constant pressure heat input, and constant volume heat output processes [20]. This Diesel cycle, in which the working fluid is the ideal air, takes place quasi-static (independent of time). In quasi-realistic cycle models, the cycle is not quasi-static (dependent on time). For this reason, irreversibilities in compression and expansion strokes, combustion efficiency, volumetric efficiency, residual gases, friction loss, and heat loss are parameters that affect the cycle performance. In general, the quasi-realistic cycle model in the literature [e.g. 5-18] consists of 1-2-3-4 consecutive points shown in Figure 1 and it is assumed that the conditions at point 1 are the same as atmospheric (initial) conditions. In this study, this cycle model has been modified and developed. For this, after point 4, point 5 expressing the quasi-realistic exhaust gas conditions were created and 5-0-1 consecutive points were used for exhaust-intake (gas exchange) strokes. Thus, the quasi-realistic Diesel cycle model in figure 1 was created. In Figure 1, " $s$ " denotes the reversible processes in the reversible cycle.
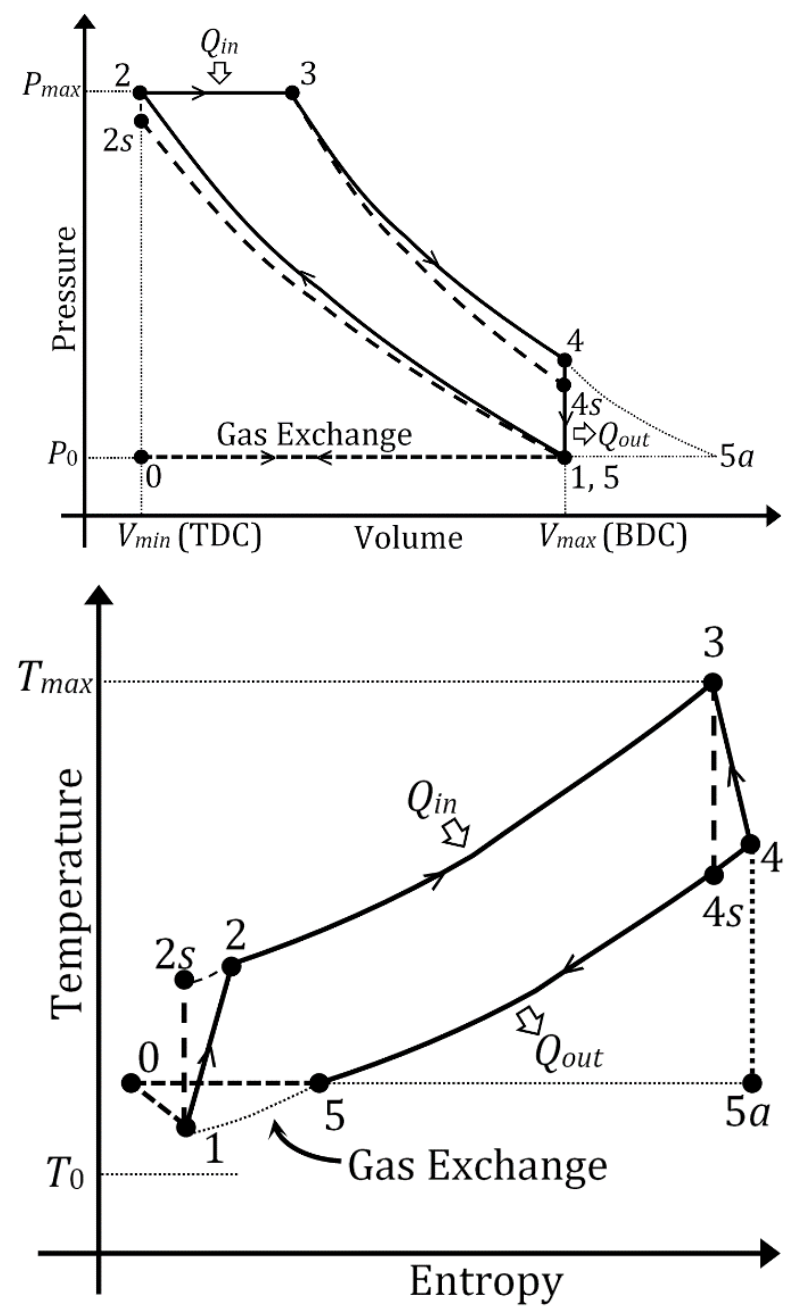

Figure 1. P-V and T-S diagrams of the irreversible Diesel Cycle

In the P-V diagram in Figure 1, it is assumed that 
the gas exchange process takes place at constant pressure (unthrottled cycle state). The intake process takes place at a pressure below atmospheric pressure and the exhaust process at a pressure above atmospheric pressure. However, in such models, the pressures of the intake and exhaust processes can be considered as atmospheric pressure. The temperature at point 0 in the absorption process is the exhaust gas temperature and is higher than the atmospheric temperature. The mixing of atmospheric air with residual exhaust gas causes the temperature at point 1 to be lower than the temperature at point 0 but higher than the atmospheric temperature. The cycle calculations are made according to the temperature at point 1. However, the main problem here is now creating a model for determining the exhaust gas temperature. Assuming that the pressure and temperature do not change during the exhaust process, a temperature lower than the end of expansion temperature should be determined as the exhaust temperature. In all studies in the literature, the temperature at point 4 is used as the exhaust temperature. However, this acceptance is unrealistic. As simple modeling, it can be assumed that the exhaust event occurs through the blowdown and exhaust processes. Actually, towards the end of the expansion process, the exhaust valve opens and there is a sudden pressure drop, which is called blowdown. Then, the exhaust process takes place at constant pressure. Modeling the blowdown process is important, as most of the exhaust gases are removed from the cylinder during the blowdown process. Using isentropic relations, the exhaust gas temperature is modeled as point 5 . A relative point $5 \mathrm{a}$ is created for this modeling. This relative point $5 a$ was modeled and the temperature at point 5 , ie the exhaust temperature, was modeled. Assuming that an isentropic process takes place between 4$5 a$, the temperature at point $5 a$ can be calculated as follows [19-20].

$T_{e x}=T_{5 a}=T_{5}=T_{4}\left(\frac{P_{0}}{P_{4}}\right)^{1-\left(\frac{c_{v}}{c_{p}}\right)_{r e s}}$

Thanks to the exhaust temperature model used in this model, the point 1 temperature, which is considered as the cycle initial temperature, is modeled more realistically. Thus, it may be possible to obtain more realistic results by using this gas-exchange model in parametric comparison studies on internal combustion engines.

\subsection{Working fluid model}

The classical Diesel cycle is closed and therefore the mass of the working fluid is constant. In the quasi-realistic Diesel cycle, it is assumed that besides the gas exchange process, fuel injection takes place at the end of the compression stroke (point 2). Qualitative load control is performed in actual Diesel engines. In Diesel engines, the air entering the cylinder is not intervened and the fuel amount is changed to change the output power of the engine [20]. In Diesel engines, the cylinder is only filled with air during the intake stroke. The fuel-injected at the end of compression mixes with the compressed air and ignites. Therefore, the mass of the working fluid in the compression stroke (points 1-2) and the mass of the working fluid after the compression stroke are not equal. The masses of the working fluid in the compression stroke and after the compression stroke are $m_{m i x 1}$ and $m_{m i x 2}$, respectively. Some residual gas mass $\left(m_{r}\right)$ remains in the cylinder after the exhaust stroke (point 0 ) in the cycle. The air mass $\left(m_{a}\right)$ entering into the cylinder during the intake stroke (0-1 point) mixes with $m_{r}$ to form $m_{\text {mix } 1}$. At the end of compression stroke, the fuel mass $\left(m_{f}\right)$ is injected into $m_{m i x 1}$ and $m_{m i x 2}$ mass is created [3, 23].

$m_{\text {mix } 1}=m_{a}+m_{r}$

$m_{\text {mix } 2}=m_{a}+m_{r}+m_{f}$

In the model created, it was assumed that the fuel was injected into the cylinder at the end of the compression stroke and the temperature and pressure changes in the mixture were ignored. It is assumed that the mixture at the end of the combustion is residual gas and that the residual gas consists of a mixture of $\mathrm{CO}_{2}, \mathrm{H}_{2} \mathrm{O}$ and $\mathrm{N}_{2}$ formed by the stoichiometric complete combustion of the fuel. In this study, it was assumed that n-hexadecane $\left(\mathrm{C}_{16} \mathrm{H}_{34}\right)$ was used as fuel. The stoichiometric ratio of the complete combustion equation is as follows:

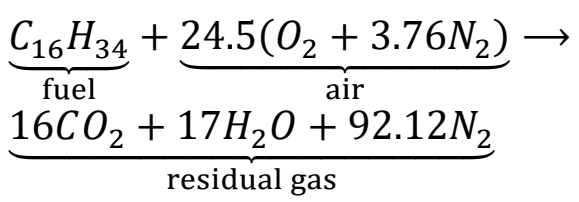


The residual gas fraction $(\psi)$ is generally defined as the ratio of the mass of the residual gas to the total mass. Also, the mass of the residual gas is expressed according to the change in compression ratio, pressure, and temperature (Eq.5) [20]. In the literature, the residual gas fraction is generally accepted as a constant value. While the gas fraction is between $3 \%$ and $7 \%$ at full load, it can rise to $20 \%$ at partial loads [21]. Since the compression ratio is high in Diesel engines, the residual gas fraction is relatively low.

$\psi=\frac{m_{r}}{m_{a}+m_{r}}=\frac{1}{r_{c}} \frac{T_{4}}{T_{5}} \frac{P_{0}}{P_{4}}$

The equivalence ratio $(\phi)$ is obtained by dividing the stoichiometric air-fuel ratio by the actual air-fuel ratio $\left(x_{A F S}\right)(\mathrm{Eq} 6)$ [3]. In Diesel engines, the load control is provided by changing the $(\phi)$ value, and the mixture is made leaner $(\phi<1)$ by reducing the amount of fuel injected for load adjustment [3].

$\phi=\frac{x_{A F s}}{m_{a} / m_{f}}$

The mass $\left(m_{a}\right)$ of the air taking into the cylinder during the intake stroke varies according to the volumetric efficiency $\left(\eta_{v o l}\right)($ Eq. 7$)$. In naturally aspirated engines, theoretically, the air takes into the displacement volume $\left(v_{d}\right)$ of the cylinder. Its density $\left(\rho_{a, T_{1}}\right)$ decreases as it mixes with the residual gas that is hotter than the air taking into the cylinder.

$m_{a}=\eta_{v o l} \rho_{a, r e f} v_{d}=\rho_{a, T} v_{d}$

$\rho_{a, T_{1}} \cong 7.2677-1.068 \ln T_{1}$

$\eta_{\text {vol }} \approx 1-0.003\left(T_{1}-T_{0}\right)$

Accordingly, Eq. 1 and Eq. 2 can also be expressed as follows.

$m_{\text {mix } 1}=m_{a}\left(\frac{1}{1-\psi}\right)$

$m_{\text {mix } 2}=m_{a}\left(\frac{1}{1-\psi}+\frac{\phi}{x_{A F S}}\right)$

Any " $i$ " fluid is expressed below based on time (engine speed).

$\dot{m}_{i}=\frac{m_{i} N}{120}$

\subsection{Specific heat model}

In classical thermodynamics, the working fluid of the cycles is ideal air and its specific heat is constant. In the cycles in finite-time thermodynamics, the specific heat of the working fluid can be considered as a constant or temperature-dependent variable. Ideal air is widely used as the working fluid in the literature. However, the working fluid can also be modeled as air-fuel or air-fuel-residual gas. In this study, it is accepted that the working fluid consists of a fuel-air- residual gas mixture, and its specific heat changes according to a logarithmic function depending on the temperature (Eqs. 13 and 14). Temperaturedependent changes of specific heats for air, fuel, and waste gas were obtained from NISTJANAF thermochemical tables [21] and logarithmic functions of temperature-dependent variation of specific heats were determined with the help of trendlines (Figure 2). This logarithmic function, developed for the temperature-dependent variation of specific heats, has been preferred because of its higher accuracy compared to the linear function and its simple use compared to the polynomial function.

$$
\begin{gathered}
c_{v i}=a_{i}+b_{i} \ln T \\
c_{p i}=c_{v i}+R_{i}=\left(a_{i}+R_{i}\right)+b_{i} \ln T \\
T(\mathrm{~K}) \text { for fuel } \\
3004005006007008009001000
\end{gathered}
$$

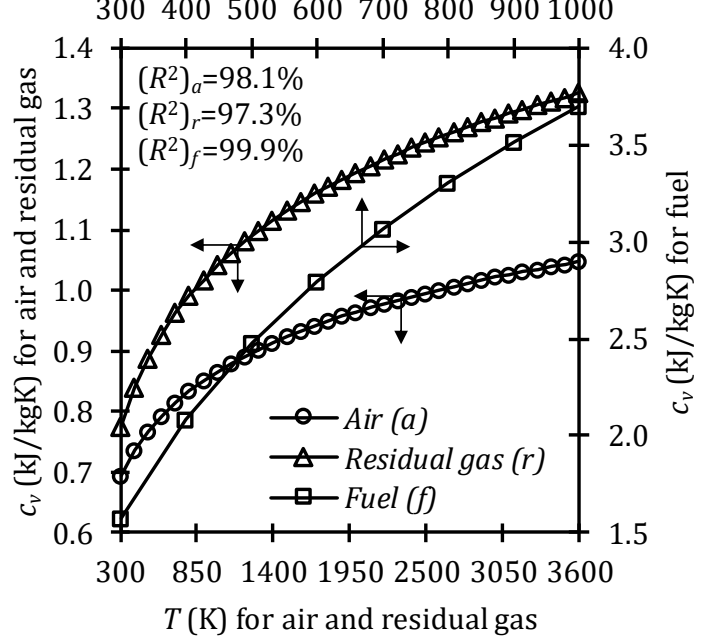

Figure 2.Temperature-dependent variation of specific heats (Created from [21])

The coefficients of the logarithmic function obtained for each fluid are presented in Table 1. To simplify the calculations, logarithmic temperature difference calculation was used to determine the specific heats for a process where the temperature changes from $i$ to $j$.

$T=\frac{T_{j}-T_{i}}{\ln \left(T_{j} / T_{i}\right)}$ 
Table 1. Coefficients for the specific heats

\begin{tabular}{lllll}
\hline$i$ & Component & $a_{i}$ & $b_{i}$ & $R_{i}$ \\
\hline$a$ & Air & -0.118 & 0.142 & 0.289 \\
$r$ & Residual & -0.490 & 0.222 & 0.306 \\
$f$ & Fuel & -8.518 & 1.769 & 0.037 \\
\hline
\end{tabular}

\subsection{Heat transfer model}

Heat loss per unit time $\left(\dot{Q}_{h t}\right)$ from the cylinder wall to the environment can be calculated according to Newton's cooling law [22-24].

$\dot{Q}_{h t}=h_{h t} A_{h t}\left(T_{m}-T_{w}\right)=h_{h t} A_{t r}\left(\frac{T_{2}+T_{3}}{2}-\right.$

$\left.T_{w}\right)$

The area where heat transfer takes place $\left(A_{h t}\right)$ is accepted as the area of the cylinder's inner surface. Cylinder inner surface area was calculated according to stroke volume $\left(v_{d}\right)$ and stroke/bore ratio $(\lambda)$. Hohenberg correlation was used for the heat transfer coefficient $\left(h_{h t}\right)$ [24].

$A_{h t}=\pi D L \frac{\varepsilon}{\varepsilon-1}+2 \pi \frac{D^{2}}{4}=2 \frac{v_{d}}{D}\left(\frac{1}{\lambda}+\frac{2 \varepsilon}{\varepsilon-1}\right)$

$h_{h t}=130\left(\frac{\varepsilon v_{d}}{\varepsilon-1}\right)^{-0.06} P_{0}^{0.8} T_{0}^{-0.4}\left(s_{p}+\right.$

$1.4)^{0.8}$

$s_{p}=\frac{L N}{30}$

\subsection{Friction model}

The lost power $\left(P_{\mu}\right)$ caused by friction (called friction power) is expressed as a function of the friction coefficient and piston speed [3].

$P_{\mu}=\mu\left(s_{p}\right)^{2}$

\subsection{Cycle initial temperature model}

At point 0 there is only residual gas in the cylinder. Air takes into the cylinder between 01 points and mixes with the residual gas. Thus, the temperature at point 1 becomes higher than the temperature at point 0 . Accordingly, the energy balance in the intake stroke is as follows $[19,22]$.

$m_{a} h_{a}=m_{1} h_{1}-m_{0} h_{0}$

$m_{a} c_{p a} T_{0}=m_{m i x 1} c_{p m i x} T_{1}-m_{r} c_{p r} T_{e x}$

Accordingly, the $T_{1}$ temperature can be calculated as follows.

$T_{1}=\frac{1-\psi}{c_{p m i x 1}}\left(c_{p a} T_{0}+\frac{\psi}{1-\psi} T_{e x}\right)$
If there were only one specific heat value for the working fluid in the cycle, the temperature $T_{1}$ could be calculated simply by using the residual gas mass and air mass.

\subsection{Irreversibility model}

$T_{2 s}$ and $T_{4 s}$ are temperatures obtained under isentropic compression and isentropic expansion conditions. Isentropic efficiency in such processes is $100 \%$. When irreversibilities occur in processes, isentropic efficiency is lower than $100 \%$. Accordingly, isentropic yields for irreversible compression and irreversible expansion processes are expressed as follows:

$\eta_{c}=\frac{W_{1 \rightarrow 2 s}}{W_{1 \rightarrow 2}}=\frac{\int_{1}^{2 s} c_{v m i x 1} d T}{\int_{1}^{2} c_{v m i x} d T} \cong \frac{T_{2 S}-T_{1}}{T_{2}-T_{1}}$
$\eta_{e}=\frac{W_{3 \rightarrow 4}}{W_{3 \rightarrow 4 s}}=\frac{\int_{3}^{4} c_{v r} d T}{\int_{3}^{4 S} c_{v r} d T} \cong \frac{T_{4}-T_{3}}{T_{4 s}-T_{3}}$

\subsection{Performance analysis model}

The main performance parameter in this study is effective power and it is expressed as follows [14-17]:

$P_{e}=P_{i}-P_{\mu}=\dot{Q}_{\text {in }}-\dot{Q}_{\text {out }}-P_{\mu}$

$\dot{Q}_{\text {in }}=\dot{m}_{\text {mix } 2} \int_{T_{2}}^{T_{3}} c_{v m i x 2} d T$

$\dot{Q}_{\text {out }}=\dot{m}_{\text {mix } 2} \int_{T_{4}}^{T_{1}} c_{p r} d T$

Intake and exhaust processes have been deliberately neglected when defining $\dot{Q}_{i n}$ and $\dot{Q}_{\text {out }} . \dot{Q}_{\text {in }}$ is also expressed as follows [14-17]:

$\dot{Q}_{i n}=\dot{Q}_{f}-\dot{Q}_{h t}$

$\dot{Q}_{f}=\eta_{\text {com }} \dot{m}_{f} H_{u}$

$\eta_{\text {com }}=-1.44738+\frac{4.18581}{\phi}-\frac{1.86876}{\phi^{2}}$

For performance comparison, thermal efficiency $\left(\eta_{t h}\right)$, specific fuel consumption $\left(b_{e}\right.$, $\mathrm{g} / \mathrm{kWh})$, power density $\left(d_{P e}, \mathrm{~kW} / \mathrm{L}\right)$ and cut off ratio $\left(r_{c u t}\right)$ are expressed as follows:

$\eta_{t h}=\frac{P_{e}}{\dot{Q}_{f}}$

$b_{e}=\frac{\left(3.6 \times 10^{6}\right) \dot{m}_{f}}{P_{e}}$

$d_{P e}=\frac{P_{e}}{v_{t}}=\frac{P_{e}(\varepsilon-1)}{\varepsilon v_{d}}$

$r_{c u t}=\frac{T_{3}}{T_{2}}=\frac{\varepsilon}{r_{\text {exp }}}$ 

Table 3. Input and output parameters used for calculations

\begin{tabular}{llll}
\hline Input Parameters & & Output Parameters & \\
\hline Constant & Variable & Calculated & Examined \\
\hline Stroke volume $\left(v_{d}\right)$ & Compression ratio $(\varepsilon)$ & Friction loss $\left(P_{\mu}\right)$ & Power density $\left(d_{P_{e}}\right)$ \\
Initial conditions $\left(P_{0}, T_{0}\right)$ & Equivalence ratio $(\phi)$ & Critical point temperatures $\left(T_{i}\right)$ & Effective \\
Friction coefficient $(\mu)$ & Stroke-bore ratio $(\lambda)$ & Fuel consumption $\left(\dot{m}_{f}\right)$ & efficiency $\left(\eta_{t h}\right)$ \\
Engine speed $(N)$ & & Combustion efficiency $\left(\eta_{c o m}\right)$ & Specific \\
Gas constants $\left(R_{i}\right)$ & Heat transfer coefficient $\left(h_{h t}\right)$ & consumption $\left(b_{e}\right)$ \\
Fuel heat value $\left(H_{u}\right)$ & Heat transfer loss $\left(\dot{Q}_{h t}\right)$ & Fuel consumption $\left(\dot{m}_{f}\right)$ \\
Cylinder wall temperature $\left(T_{w}\right)$ & & Input heat $\left(\dot{Q}_{i n}\right)$ & Cut off ratio $\left(r_{c u t}\right)$ \\
Specific heat coefficients $\left(c_{v i}\right)$ & & Output heat $\left(\dot{Q}_{\text {out }}\right)$ & Dimensionless maximum \\
Isentropic efficiency $\left(\eta_{c}, \eta_{e}\right)$ & & Effective power $\left(P_{e}\right)$ & temperature $\left(T_{\text {max }} / T_{\text {min }}\right)$ \\
& & Residual gas fraction $(\psi)$ & Dimensionless exhaust \\
& & Volumetric efficiency $\left(\eta_{v o l}\right)$ & temperature $\left(T_{e x} / T_{\text {min }}\right)$ \\
\hline
\end{tabular}

\section{Results and Discussion}

Although the mathematical model presented is for the quasi-realistic Diesel cycle, it should not be expected to calculate the performance parameters of an actual model using this model. Because in this model, the effect of combustion kinematics on performance has never been addressed. The main purpose of this model is to examine the effects of parameters that affect performance in Diesel engine cycle on engine performance. For this reason, the results obtained in calculations using the features of an actual engine are much better than the performance of the actual engine. The numerical value of the results obtained here is not important. However, the effect of any design or operating parameter change on engine performance can be easily observed.

The specifications of the Diesel-powered generator presented in Table 2 are used as a reference for comprehensive numerical analysis.

Table 2. General characteristics of the generator used in the numerical analysis

\begin{tabular}{ll}
\hline Specification & Explanation \\
\hline Engine Model & $186-$ FAE \\
Alternator Type & Monophase \\
Max. Alternator Power & $5 \mathrm{~kW}$ \\
Alternator Speed & $3000 \mathrm{rpm}$ \\
Max. Engine Power & $6.4 \mathrm{~kW}$ \\
Cooling System & Forced Air \\
Intake System & N.Aspirated \\
Stroke/Bore & $72 / 86 \approx 0.84$ \\
Compression Ratio & $19: 1$ \\
Stroke Volume & $418 \mathrm{cc}$ \\
\hline
\end{tabular}

Input and output parameters used for parametric calculations are presented in Table 3.

The values of the fixed input parameters in the calculations are presented in Table 4.
Table 4. Values of constant input parameters

\begin{tabular}{ll}
\hline Parameter & Value \\
\hline$\varepsilon$ & $418 \mathrm{cc}$ \\
$P_{0}$ & $100 \mathrm{kPa}$ \\
$T_{0}$ & $300 \mathrm{~K}$ \\
$\mu$ & $12.9 \mathrm{Ns} / \mathrm{m}$ \\
$N$ & $3000 \mathrm{rpm}$ \\
$H_{u}$ & $42780 \mathrm{~kJ} / \mathrm{kg}$ \\
$T_{w}$ & $360 \mathrm{~K}$ \\
$\eta_{c}$ & $95 \%$ \\
$\eta_{e}$ & $95 \%$ \\
\hline
\end{tabular}

In the calculations, compression ratio $(\varepsilon)$, equivalence ratio $(\phi)$, and stroke/bore ratio $(\lambda)$ were preferred as variable input parameters (Table 5).

Table 5. Values of variable input parameters

\begin{tabular}{ll}
\hline Parameter & Range \\
\hline$\varepsilon$ & 17 to 21 \\
$\phi$ & 0.7 to 1.0 \\
$\lambda$ & 0.8 to 1.2 \\
\hline
\end{tabular}

The input parameters presented above were used in Eqs. 1-35, and output parameters were calculated and graphs were obtained for examined output parameters.

Since the load in Diesel engines is provided by the change of $\phi$, increasing the $\phi$ increases the power density $\left(d_{P_{e}}\right)$. However, the increase in $\phi$ also increases the effective thermal efficiency $\left(\eta_{t h}\right)$. In other words, when evaluated in terms of effective thermal efficiency, it is more advantageous to run the engine at full load than to run it at partial load. Increasing $\varepsilon$ increases both power density and effective thermal efficiency. However, in determining $\varepsilon$, especially the maximum temperature parameter should be taken into consideration. $\lambda$ is usually 
smaller than 1 in actual Diesel engines. As $\lambda$ increases, both the power density and effective thermal efficiency decrease (Figure 3).

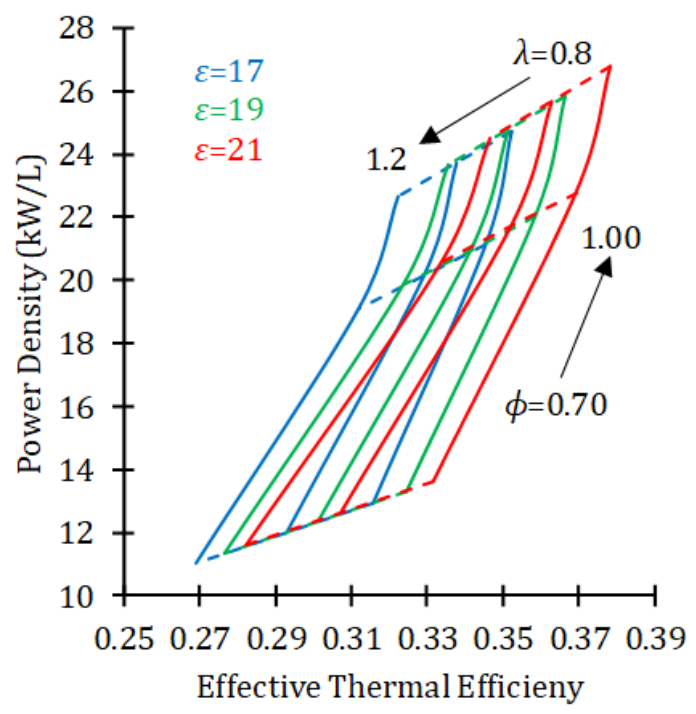

Figure 3.The effect of $\varepsilon, \phi$ and $\lambda$ on power density

For a constant engine speed, as $\phi$ increases, the load increases and so does the fuel consumption. However, increasing $\lambda$ for constant engine load almost does not affect fuel consumption. However, as the $\lambda$ increases, the effective thermal efficiency decreases. When $\varepsilon$ is increased, fuel consumption increases a little while the thermal efficiency increases (Figure 4).

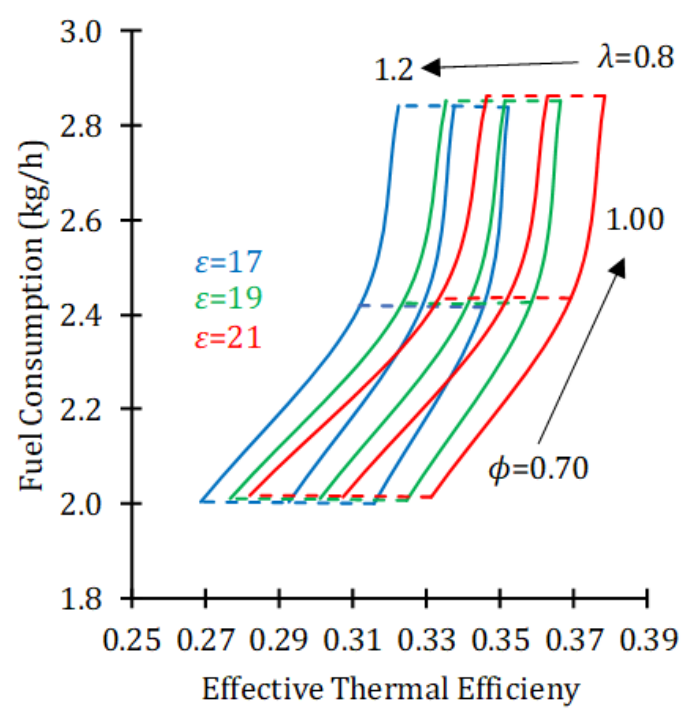

Figure 4. The effect of $\varepsilon, \phi$ and $\lambda$ on fuel consumption

Specific fuel consumption in internal combustion engines is an indicator of fuel efficiency and is desired to be as low as possible. Specific fuel consumption decreases first with the increase of $\phi$ and then increases again with the approach of $\phi$ to 1 . An increase of $\lambda$ causes an increase in specific fuel consumption.
Increasing $\varepsilon$ causes a decrease in specific fuel consumption (Figure 5).

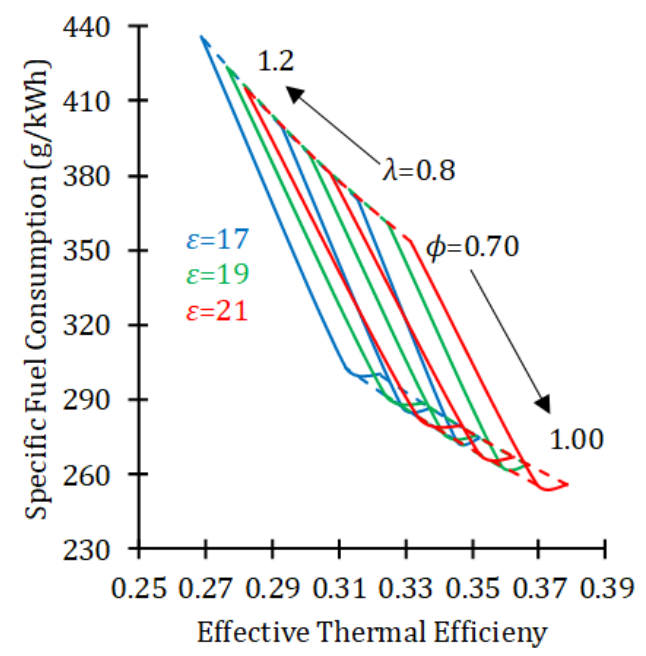

Figure 5. The effect of $\varepsilon, \phi$ and $\lambda$ on specific fuel consumption

In Diesel engines, the maximum temperature of the cycle $\left(T_{\max }\right)$ is an important parameter not for engine performance but the selection of the thermal properties of the engine material. For this reason, $T_{\max }$ should be limited according to the characteristics of the engine material. $T_{\max }$ increases as $\phi$ increases. $T_{\max }$ decreases with increasing lambda. When $\varepsilon$ increases, $T_{\max }$ increases (Figure 6).

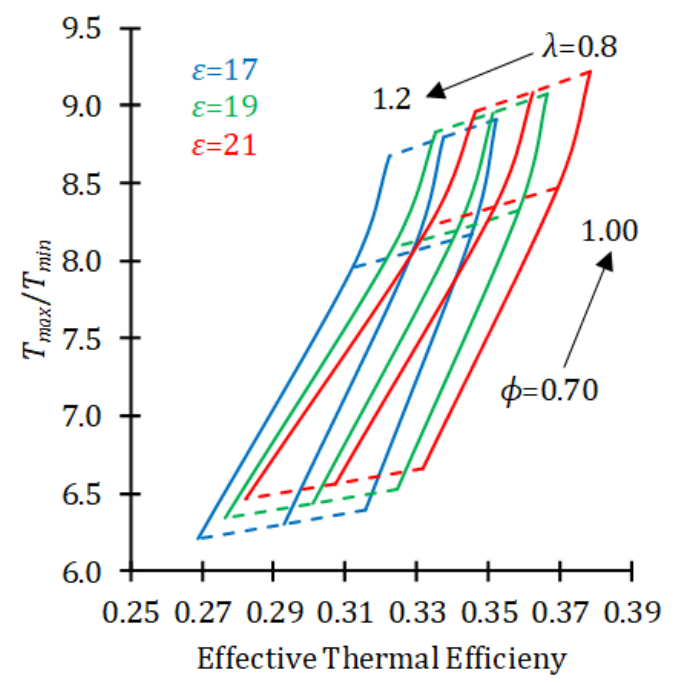

Figure 6. The effect of $\varepsilon, \phi$ and $\lambda$ on dimensionless maximum temperature

Since $\varepsilon$ is higher in Diesel engines compared to gasoline engines, the temperature after combustion is high. However, the expansion ratio in Diesel engines is smaller than the compression ratio. Therefore, $T_{e x}$ is quite high at the end of the expansion stroke. Hightemperature exhaust gas is waste heat and can be used in systems working with waste heat such as 
the organic Rankine cycle. Basically, $T_{e x}$ is not desired to be high. As $\phi$ increases, so does $T_{e x}$. As $\lambda$ increases, $T_{e x}$ decreases. As $\varepsilon$ increases, $T_{\text {ex }}$ decreases (Figure 7).

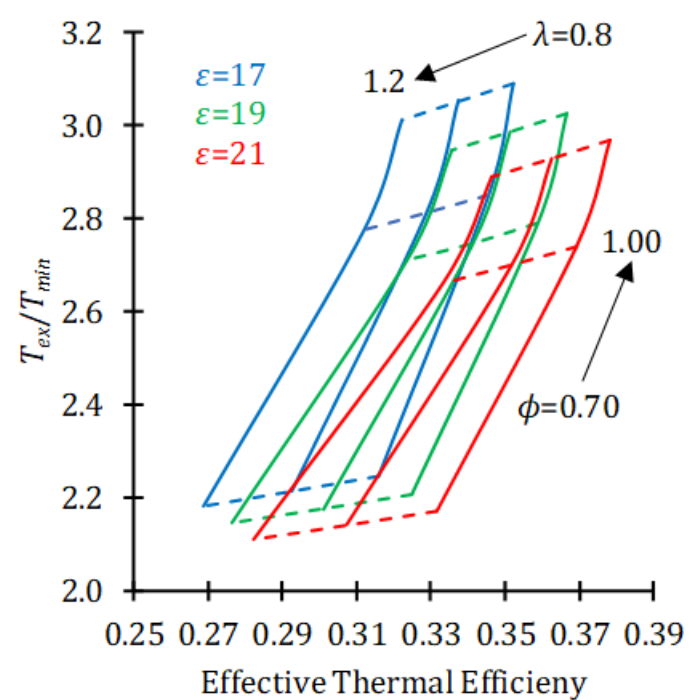

Figure 7. The effect of $\varepsilon, \phi$ and $\lambda$ on dimensionless exhaust temperature

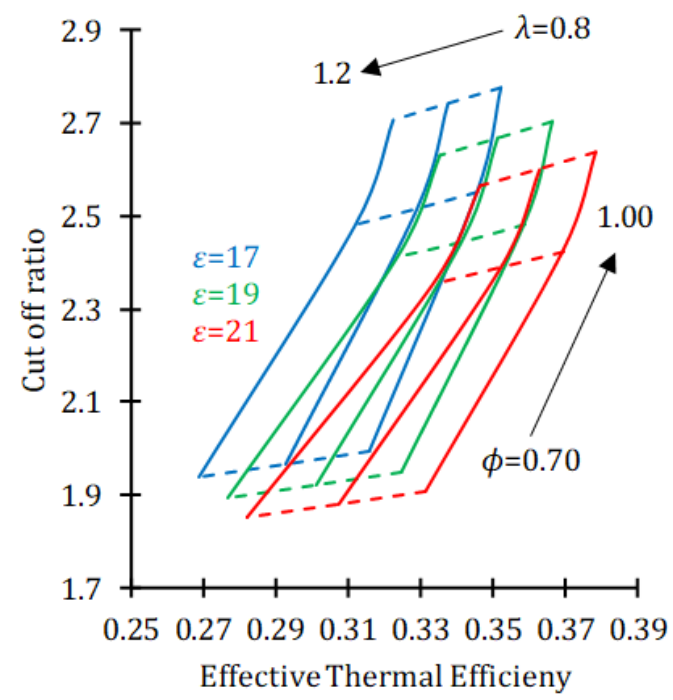

Figure 8 . The effect of $\varepsilon, \phi$, and $\lambda$ on cut off ratio

It is assumed that the pressure does not change at the heat input in the theoretical Diesel cycle due to slow combustion in actual Diesel engines. In the case of heat input at constant pressure, the expansion stroke occurring after heat input due to the piston displacement is shorter than the compression stroke. The volume change in the case of heat input at constant pressure is defined by the cut off ratio (also called pre-expansion ratio). The product of the cut off ratio $\left(r_{c u t}\right)$ and the expansion ratio is equal to the compression ratio. That is, as $r_{c u t}$ increases, the expansion ratio decreases. For this reason, $r_{\text {cut }}$ is required to be low. In the theoretical Diesel cycle efficiency expression, the smaller $r_{c u t}$, the higher the thermal efficiency. $r_{\text {cut }}$ increases as $\phi$ increases. $r_{c u t}$ decreases with increasing $\lambda . r_{c u t}$ decreases as $\varepsilon$ increases (Figure 8).

As a general evaluation, the effect of the increase of $\varepsilon, \phi$, and $\lambda$ on the examined engine performance parameters is summarized in Table 6.

Table 6 The effect of the increase of $\varepsilon, \phi$, and $\lambda$ on the engine performance parameters

\begin{tabular}{|c|c|c|c|c|c|c|c|}
\hline & $d_{P_{e}}$ & $\dot{m}_{f}$ & $b_{e}$ & $T_{\max }$ & $T_{e x}$ & $r_{\text {cut }}$ & $\eta_{t h}$ \\
\hline $\bar{\varepsilon}$ & $\bar{\uparrow}$ & $\uparrow^{*}$ & $\downarrow$ & $\bar{\uparrow}$ & $\downarrow$ & $\downarrow$ & $\bar{\uparrow}$ \\
\hline$\phi$ & $\uparrow$ & $\uparrow$ & $\downarrow^{\mathrm{b}} \uparrow^{\mathrm{a}}$ & $\uparrow$ & $\uparrow$ & $\uparrow$ & $\uparrow$ \\
\hline$\lambda$ & $\downarrow$ & $\leftrightarrow$ & $\uparrow$ & $\downarrow$ & $\downarrow$ & $\downarrow$ & $\downarrow$ \\
\hline
\end{tabular}

The load increases with the increase of $\phi$. For this reason, the increase in $\phi$ causes all performance parameters (except $b_{e}$ ) to increase. For this reason, in stationary systems such as power generators, it is advantageous to operate the engine in the full load area as much as possible. Engine performance and fuel economy deteriorate at partial loads, that is when $\phi$ is less than 1. For the condition where $\phi$ is constant when $\varepsilon$ is increased, while $d_{P_{e}}, T_{\max }$ and $\eta_{t h}$ increase, $b_{e}, T_{e x}$, and $r_{c u t}$ decrease. However, because $T_{\max }$ is not desired to be high, $T_{\max }$ is a parameter that limits $\varepsilon$. Because the engine material must be resistant to $T_{\max }$. When $\lambda$ is increased, all parameters (except $b_{e}$ and $\dot{m}_{f}$ ) decrease. Although the increase in $\lambda$ does not affect on $\dot{m}_{f}$, it causes an increase in $b_{e}$. Since $\phi$ is an operating parameter related to the load in Diesel engines, it is determined concerning the load requested from the engine and it is desired to have a value as close to 1 as possible for high performance. $\varepsilon$ and $\lambda$ are design parameters and these values need to be optimized and determined.

The validity of the model was tested by comparing the obtained results with the results of Orman et al. They [25] conducted an experimental study on a Diesel engine with equivalent properties to engine used as a reference in this study[25]. The comparison of the results obtained in their studies with the results we obtained is presented in Figure 9.

It can be seen in the results in Figure 9 that there is a significant difference between the results 
obtained by calculations and the experimental data. The power calculated here is $50 \%$ higher than the experimental power. As a result, the power density was also achieved approximately $50 \%$ higher. Although the presented model is called quasi-realistic, this model is not sufficient to obtain the performance parameters of the actual engine. However, since parameters such as heat transfer losses, friction, gas-exchange are taken into account in this model, the results obtained by determining the effects of parameters such as compression ratio, equivalence ratio, stroke-bore ratio on engine performance can guide the engine designer.

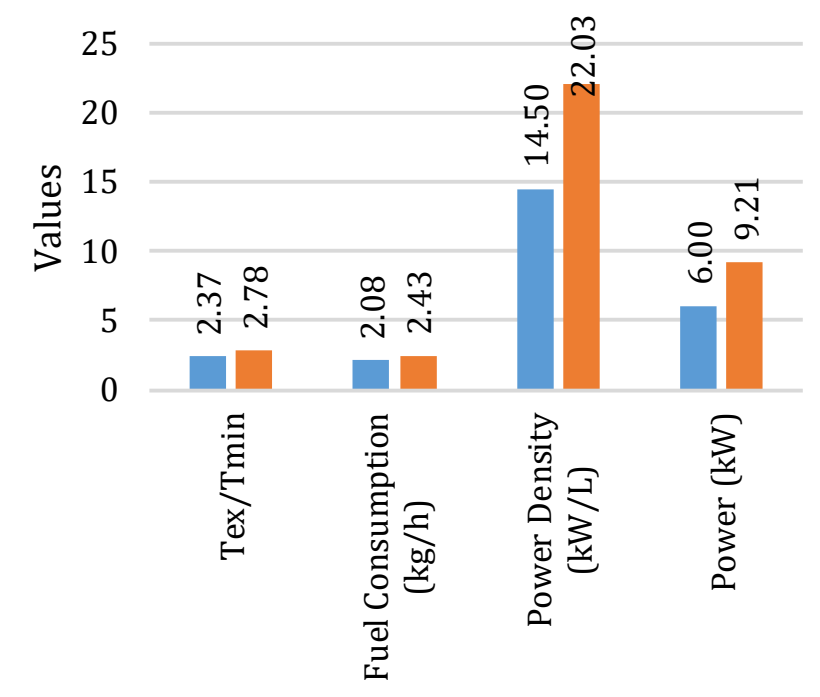

Parameters

Ref [25] $\quad$ This study

Figure 9. Comparison of the obtained results with experimental data

\section{Conclusions}

In this study, a mathematical model is created using finite-time thermodynamics for a quasirealistic Diesel cycle engine. Irreversibilities, heat transfer losses, friction, and gas exchange process are taken into consideration in the mathematical model created. Especially the exhaust temperature model presented in the created model has carried this study one step further than the studies in the literature. Because, thanks to the exhaust temperature model, the cycle starting temperature can be determined more realistically, and thus the exhaust temperature has become a parameter that affects engine performance. The fuel-airresidual gas mixture was preferred as the working fluid. The effect of change in equivalence ratio, stroke-bore ratio, and compression ratio on engine performance was examined. Characteristics of a Diesel engine of a power generator are used for the basic dimensions of the Diesel engine. The results obtained were compared with the results in the literature. As a result, it is foreseen that this model will not be used to obtain the performance parameters of an actual engine, but can be a powerful tool to examine the effects of design and operating parameters on engine performance. It has been observed that the results obtained with this model can guide engine designers.

\section{Nomenclature}

$\dot{Q}_{h t} \quad$ Heat loss flow

$\dot{Q}_{\text {in }}$ Input heat flow

$\dot{Q}_{\text {out }}$ Output heat flow

$\dot{m}_{i} \quad$ Mass flow of $i$

$h_{h t} \quad$ Heat trasfer coefficient

$A_{h t} \quad$ Heat transfer area

$P_{0} \quad$ Atmospheric pressure

$P_{e} \quad$ Effective power

$P_{i} \quad$ Indicated power

$P_{\mu} \quad$ Friction power

$R_{i} \quad$ The gas constant of $i$

$T_{\text {ex }} \quad$ Exhaust temperature

$T_{e x} \quad$ Maximum temperature

$T_{w} \quad$ Cylinder Wall temperature

$b_{e} \quad$ Specific fuel consumption

$c_{p i} \quad$ Specific heat of $i(P=$ constant $)$

$c_{v i} \quad$ Specific heat of $i$ for $(V=$ constant $)$

$d_{P e} \quad$ Dimensionless power

$m_{i} \quad$ Mass of $i$

$r_{c u t}$ Cut-off ratio

$s_{p} \quad$ Piston speed

$v_{d} \quad$ Displacement volume

$x_{A F S} \quad$ Stoichiometric air-fuel ratio

$\eta_{c} \quad$ Isentropic efficiency (compression)

$\eta_{\text {com }}$ Combustion efficiency

$\eta_{e} \quad$ Isentropic efficiency (expansion)

$\eta_{t h} \quad$ Thermal efficiency

$\eta_{\text {vol }} \quad$ Volumetric efficiency

$\rho_{a, T} \quad$ Air density for $T$ temperature

NOx Nitrogen-oxides

PM Particle matter

WHO World Health Organization

$\lambda \quad$ Stroke-bore ratio

$\psi \quad$ Residual gas fraction

$\phi \quad$ Equivalence ratio 


\section{References}

1. IARC Working Group, " Diesel and Gasoline Engine Exhausts and Some Nitroarenes", IARC Monographs on the Evaluation of Carcinogenic Risks to Humans. IARC Monographs on the Evaluation of Carcinogenic Risks to Humans, 105, 9, 2014.

2. Reif, K., “ Diesel engine management”, Springer Vieweg, 2014.

3. Arabac1, E., "Thermodynamic analysis of endoreversible six-stroke Otto cycle with respect to equivalence ratio, residual gas fraction and mean piston speed", International Journal of Automotive Engineering and Technologies, 8-1, 1-10, DOI: 10.18245/ijaet.500789, 2019.

4. Kaushik, S.C., Tyagi, S.K., Kumar, P., "Finite time thermodynamics of power and refrigeration cycles". Springer International Publishing, 2017.

5. Ebrahimi, R., "Effect of Volume Ratio of Heat Rejection Process on Performance of an Atkinson Cycle", Acta Physica Polonica A, 133, 201-205, DOI:10.12693/APhysPolA.133.201, 2018.

6. You, J., Chen, L., Wu, Z., Sun, F., "Thermodynamic performance of Dual-Miller cycle (DMC) with polytropic processes based on power output, thermal efficiency and ecological function", Science China Technological Sciences, 61, 453-463, DOI:10.1007/s11431-017-9108-2, 2018.

7. Ge, Y.L., Chen, L., Sun, F.R., "Ecological Optimization of an Irreversible Otto Cycle With Variable Specific Heats of Working Fluid", Proceedings of the Chinese Society of Engineering Thermophysics on Engineering Thermophysics and Energy Utility, Wuhan, China, $5-7$,

DOI: 10.1615/TFEC2017.fna.018308, 2011.

8. Ebrahimi, R., "Effects of mean piston speed, equivalence ratio and cylinder wall temperature on performance of an Atkinson engine" Mathematical and Computer Modelling, 53, 1289-1297, DOI:10.1016/j.mcm.2010.12.015, 2011.

9. Ebrahimi, R., "Thermodynamic Modeling of an Atkinson Cycle with respect to Relative Air-Fuel Ratio, Fuel Mass Flow Rate and Residual Gases", Acta Physica Polonica, A., 124, 29-34, DOI:10.12693/APhysPolA.124.29,
2013.

10. Ge, Y., Chen, L., Sun, F., Wu, C., "Thermodynamic simulation of performance of an Otto cycle with heat transfer and variable specific heats of working fluid", International Journal of Thermal Sciences, 44, 506-511, DOI:10.1016/j.ijthermalsci.2004.10.001, 2005. 11. Gonca, G., "Comparative performance analyses of irreversible OMCE (Otto Miller cycle engine)-DiMCE ( Diesel miller cycle engine)-DMCE (Dual Miller cycle engine)" Energy, 109, 152-159, DOI:10.1016/j.energy.2016.04.049, 2016.

12. Zhao, Y., and Chen, J., "An irreversible heat engine model including three typical thermodynamic cycles and their optimum performance analysis" International Journal of Thermal Sciences, 46, 605-613, DOI:10.1016/j.ijthermalsci.2006.04.005, 2007. 13. Dobrucali, E., "The effects of the engine design and running parameters on the performance of an Otto-Miller Cycle engine". Energy, 103, 119-126, DOI:10.1016/j.energy.2016.02.160, 2016.

14. Gonca,G., Sahin, B., Ust, Y., "Performance maps for an air-standard irreversible Dual-Miller cycle (DMC) with late inlet valve closing (LIVC) version" Energy, 54, 285-290, DOI:10.1016/j.energy.2013.02.004, 2013.

15. Gonca, G., and Sahin, B., "The influences of the engine design and operating parameters on the performance of a turbocharged and steam injected Diesel engine running with the Miller cycle", Applied Mathematical Modelling, 40, 3764-3782, DOI: 10.1016/j.apm.2015.10.044, 2016.

16. Gonca, G., and Dobrucali, E., "Theoretical and experimental study on the performance of a Diesel engine fueled with Diesel-bio Diesel blends", Renewable Energy, 93,

658-666,

DOI:10.1016/j.renene.2016.03.037, 2016.

17. Gonca, G., "Effects of engine design and operating parameters on the performance of a spark ignition (SI) engine with steam injection method (SIM)", Applied Mathematical Modelling, 44, 655-675, DOI:10.1016/j.apm.2017.02.010, 2017.

18. Hernández, A.C., Roco, J.M.M., Medina, A., Velasco, S., "An irreversible and optimized four stroke cycle model for 
automotive engines", European Journal of Physics, 17, 11, 1996.

19. Ferguson, C. R., Kirkpatrick, A. T. "Internal combustion engines: applied thermosciences", John Wiley \& Sons, 2015.

20. Pulkrabek, W. W. "Engineering fundamentals of the internal combustion engine", Pearson, 2004.

21. Chase, M. W., Davies, C. A., Downey, J. R., Frurip, D. J., McDonald, R. A., Syverud, A. N. "NIST JANAF Thermochemical Tables ver. 1.0". US Dept. of Commerce, 1985.

22. Boles, M., Cengel, Y. "Thermodynamics: an engineering approach". New York: McGraw-Hil 1 Education, 2014.

23. Arabac1, E., "Simulation and performance analysis of a spark ignition engine using gasoline and LPG as fuel", Journal of the Faculty of Engineering and Architecture of Gazi University, 36:1, 447-457, 2021.

24. Merker, G. P., Schwarz, C., Stiesch, G., Otto, F. "Simulating Combustion: Simulation of combustion and pollutant formation for enginedevelopment". Springer Science \& Business Media, 2005.

25. Özdalyan B., Orman R.Ç., "Experimental Investigation of the Use of Waste Mineral Oils as a Fuel with Organic-Based Mn Additive". Energies. 11(6):1512, DOI: 10.3390/en11061512, 2018. 